\title{
Polymer-modified mortars for corrosion protection at offshore wind energy converters
}

\author{
Ludger Lohaus ${ }^{a}$, Hannes Weicken ${ }^{b}$ \\ Institute of Building Materials Science, Leibniz Universität Hannover, Appelstraße 9A, 30167 \\ Hannover, Germany \\ alohaus@baustoff.uni-hannover.de, bh.weicken@baustoff.uni-hannover.de
}

Keywords: offshore wind energy, polymer-modified mortar, corrosion protection, durability, chloride migration, freeze-thaw

\begin{abstract}
The importance of renewable energy for our world's energy supply is steadily increasing. Starting last year, offshore wind parks are being developed along the German coastline following the success achieved in the onshore wind energy. The first German offshore wind energy park is be erected on the Alpha Ventus test field near the isle of Borkum, where the depth of the sea amounts to 30 meters. Due to the hazardous conditions associated with the sea water, many challenges regarding corrosion control have to be met. With the combined effects of sea water, varying moisture conditions and impact damages caused by ice and flotsam, the conventional methods of corrosion protection with mean thicknesses of $1000 \mu \mathrm{m}$ will not suffice to protect the steel for an operating life expectancy of 25 years. As a result, the thickness of the various construction elements need to be increased beforehand leading to an excessive usage of steel. For the new corrosion protection system presented in this paper, a layer made of high performance mortar with a thickness of about ten millimeters will be sufficient to protect the steel. To unfold its protecting effect, the mortar needs to comply with stringent requirements such as exhibiting high resistance to chloride ingress, frost and abrasion.
\end{abstract}

\section{Motivation}

The anti-corrosive effect exhibited by cement bonded materials is well known in reinforced concrete engineering. Due to the alkaline milieu in the mortar, a passive layer is created on the surface of the steel, thereby preventing it from rusting. On the other hand, carbonation and penetration of chlorides neutralize this protective characteristic resulting into rusting of the steel. Cracking and even microcracking of the mortar affect the durability of the mortar and as a result the corrosion protection of the steel construction may be drastically impaired. Due to these reasons, the mortar layer must comply the following requirements. Firstly, the layer must be dense to hinder chlorides and moisture penetrating to the steel surface. Secondly, the mortar layer needs to have a high strength to avoid cracking due to the impacts of flotsam and ice. Another important point that needs to be considered is the shrinkage behaviour of the mortar. A reduction in the length of the mortar layer is hindered by the steel tower, thus leading to tensile stresses in the mortar which could result into cracking.

Hence, the task is to create a high performance mortar that fulfills the mentioned requirements and also allows construction of offshore wind energy converters without oversizing the steel sections.

By polymer modification of the mortar, the fresh as well as the hardened mortar properties can be positively influenced. It is important to ensure good workability, high compressive and flexural strength and low permeability. 


\section{Experimental programme}

The aim of this research is to analyze how modifications of concrete by polymer addition influence the properties of mortar with regard to corrosion protection. For this purpose two different types of dispersions were used, a styrene-acrylate and a styrene-butadiene. By variation of polymer concentrations the optimal dosage of the polymer dispersion could be identified. Detail investigations of the fresh as well as hardened mortar properties were realized. Regarding the fresh mortar properties, results of consistency examinations and determination of air volume content are presented. The results from the investigations of the hardened mortar properties, including compressive strength, flexural strength and resistance against chloride, water ingress and freezethaw-cycles are also presented.

As an initial composition, high performance mortar was used. This mortar possesses a very dense structure because of the addition of fly ash and silica fume, even before the addition of polymers. The water/cement ratio of 0.39 is kept constant in all mixtures. The dosage of polymer dispersions constitutes $10 \%$ and $20 \%$ and is denoted as mass percentage of the cement content.

\section{Properties of fresh mortar}

Due to the desired thin layer of the mortar (about $10 \mathrm{~mm}$ ), a very fluid but still sedimentation free mortar is needed. It was planned to fill the mortar into a textile formwork which is wrapped around the steel tower. Whether a certain mortar mixture is suitable to fill such a narrow space can be tested with a specifically developed testing formwork [8]. The initial mortar composition was successfully filled into the testing formwork, confirming the fact that the fresh mortar properties should not show dramatic changes by the addition of polymers. An important factor to determine a successful filling process is the hopper flow time of the mortar, from which conclusions concerning the viscosity and the workability of the mortar can be drawn.

In Fig. 1 the hopper flow time of the various mortars is shown. It can clearly be seen that the addition of the polymer dispersions has no significant effect on the hopper flow time. After adding the styrene-acrylate, the hopper flow time of the reference mortar composition decreased slightly from $42.8 \mathrm{~s}$ to $36.4 \mathrm{~s} / 40.0 \mathrm{~s}$ without segregation of the mortar. Furthermore, the addition of styrenebutadiene has led to a decrease in the hopper flow time, which can be attributed to the improvement of workability after the addition of the polymer dispersion. However, the two polymer types showed different tendencies in the hopper flow time. With styrene-butadiene, the hopper flow time decreases with higher polymer content, whereas the hopper flow time increases with a higher content of styrene-acrylate.

A certain amount of air-entraining into the mortar during the mixing process is not critical for the planned application and could even enhance the resistance against exposures to sea conditions. Firstly, the air voids break the capillary system and raise the resistance against water ingress. Secondly, the pores increase the expansion space for the freezing water, thereby optimizing the frost resistance and the tightness of the mortar.

The air content, which was $1.2 \%$ for the initial mortar composition, was not affected by the addition of the polymer dispersions. Since the mortar is free-flowing and has self-compacting properties, it is able to deaerate nearly completely. Moreover, it might be possible that the polymer dispersion already contains a defoaming agent, which could have led to a decrease in the air void content in the fresh mortar. 

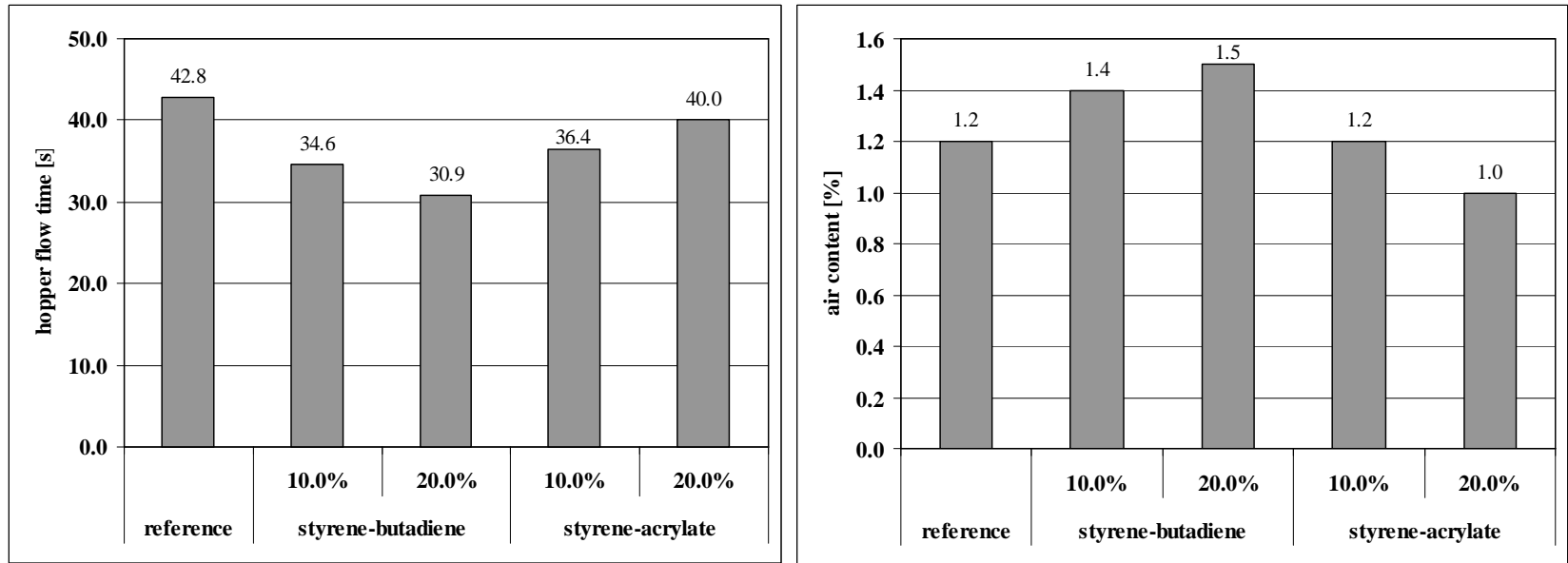

Figure 1: Hopper flow time and air content of the polymer modified mortar compositions

The aim of this research is to analyze how modifications of concrete by polymer addition influence the properties of mortar with regard to corrosion protection. For this purpose two different types of dispersions were used, a styrene-acrylate and a styrene-butadiene. By variation of polymer concentrations the optimal dosage of the polymer dispersion could be identified. Detail investigations of the fresh as well as hardened mortar properties were realized. Regarding the fresh mortar properties, results of consistency examinations and determination of air volume content are presented. The results from the investigations of the hardened mortar properties, including compressive strength, flexural strength and resistance against chloride, water ingress and freezethaw-cycles are also presented.

As an initial composition, high performance mortar was used. This mortar possesses a very dense structure because of the addition of fly ash and silica fume, even before the addition of polymers. The water/cement ratio of 0.39 is kept constant in all mixtures. The dosage of polymer dispersions constitutes $10 \%$ and $20 \%$ and is denoted as mass percentage of the cement content.

\section{Properties of hardened mortar}

In addition to the fresh mortar properties, the hardened mortar properties are also of great importance for guaranteeing proper protection against the effects of corrosion. These properties are responsible for ensuring that the mortar layer permanently remains around the steel tower in order to protect it against the impacts of the sea water.

Compressive and flexural strength. In comparison with the initial mortar composition, the compressive strength does not decrease significantly due to the addition of polymer dispersions. The high compressive strength of approximately $86 \mathrm{MPa}$ is expected to prevent the spalling of the corrosion protection layer caused by the impact of flotsam or ice, thus inhibiting the permeation of chlorides through occurring cracks.

The addition of styrene-acrylate causes a significant increase in the bending tensile strength (Fig.2). An increase from 7.4 MPa to $11.7 \mathrm{MPa}$ at the age of 28 days can be observed. This value is reached with the $10 \%$ as well as the $20 \%$ dosage. Adding styrene-butadiene does not result in a considerable increase in the flexural strength, which is in compliance with the conclusion that not all of the polymer modifications bring about the desired properties. The required properties of the modified mortar are dependent up on the used dispersion and the composition. However, this can only be determined from experiments.

While the increase in the flexural strength is desirable due to the oscillating motion of the steel tower, the integration of textile reinforcement remains necessary in order to absorb the tensile stresses. 

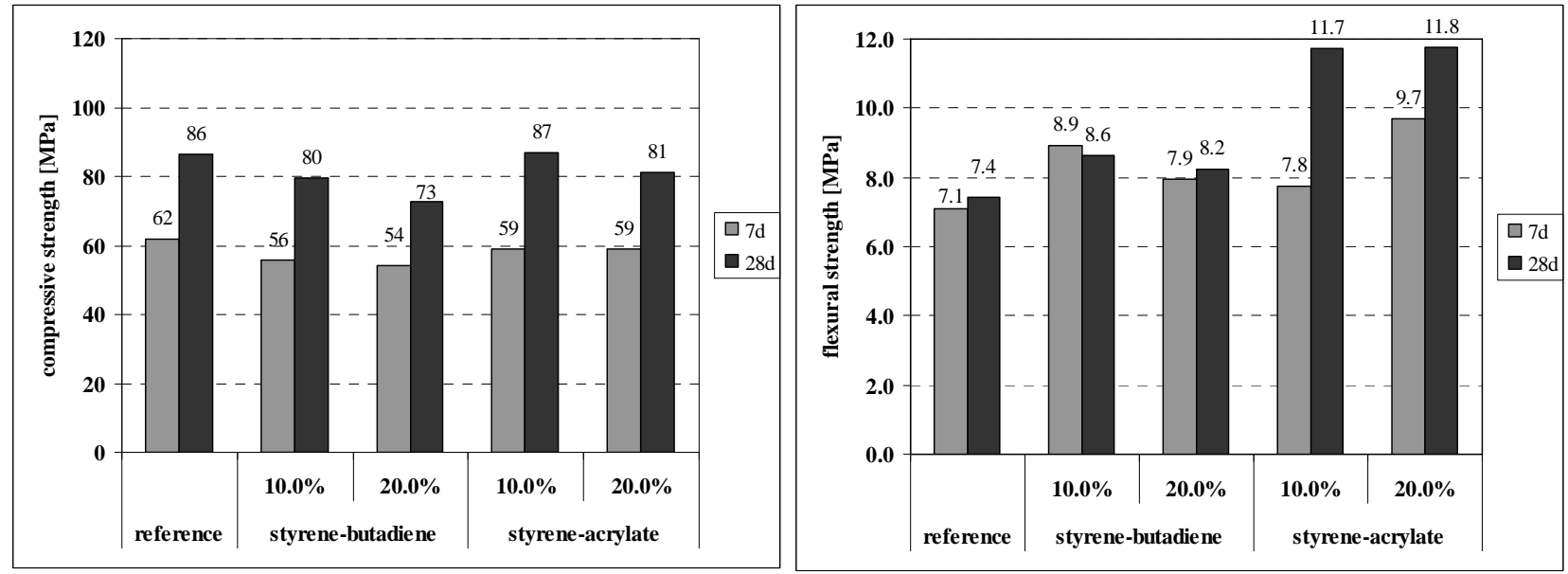

Figure 2: Results of compressive and flexural tests at the age of 7 and 28 days

Water permeability test. Depending on the sea water level, the mortar used for corrosion protection can become wet or completely dry. Continuous fluctuations in moisture content increase the intrusion of damaging substances, which might attack the mortar as well as the steel tower.

For the test method according to the DIN EN 12390-8 a water pressure of 5 bar is applied on the specimen at a testing age of 28 days. After stripping, the specimens were stored under water with a constant temperature of $20^{\circ} \mathrm{C}$. According to the DIN standard only the maximum penetration depth of water should be measured. However, to achieve a better comparison, the average value of penetration depth is presented in Fig. 3. After 28 days, a penetration depth of $3.2 \mathrm{~mm}$ to $5.4 \mathrm{~mm}$ was measured. Clear distinctions can be made only after the second testing program. Therefore, the test specimens were stored for 28 days under water, too. A further storage followed for 14 days in a climate chamber at $20^{\circ} \mathrm{C}$ and $65 \%$ relative humidity. Due to these storage conditions, the capillary pores were going to dry up at this time contrary to the water-filled pores after 28 days storage under water.

The "dry" mortar is able to absorb water quickly. This effect was further magnified by the applied pressure of 5 bar. For the reference mortar composition, a 10 times higher depth of penetration was measured by changing storage condition from storage only under water to a storage under water followed by a dry storage.

As a result of drying-out the specimens for 14 days, it was possible that a thin film of polymer dispersions was formed. The polymers that are made of highly effective hydrophobic thermoplastics, are accumulated on the surfaces of the pores, thereby inhibiting the penetration of water into the mortar.

For this reason, the penetration depths are much lower in comparison with the reference mortar composition. For the mixtures with $20 \%$ concentration of styrene-butadiene and styrene-acrylate, the depth of water penetration after dry storage is lower compared to the depth after storage under water. This is contrary to the results of the reference mortar composition and shows that a drying out of the mortar is necessary to activate the effects of the polymer dispersions.

The investigation of water permeability clearly shows a considerable improvement in the modified mixtures when compared to the reference mortar composition. This improvement makes the mortar more resistant to water ingress. 


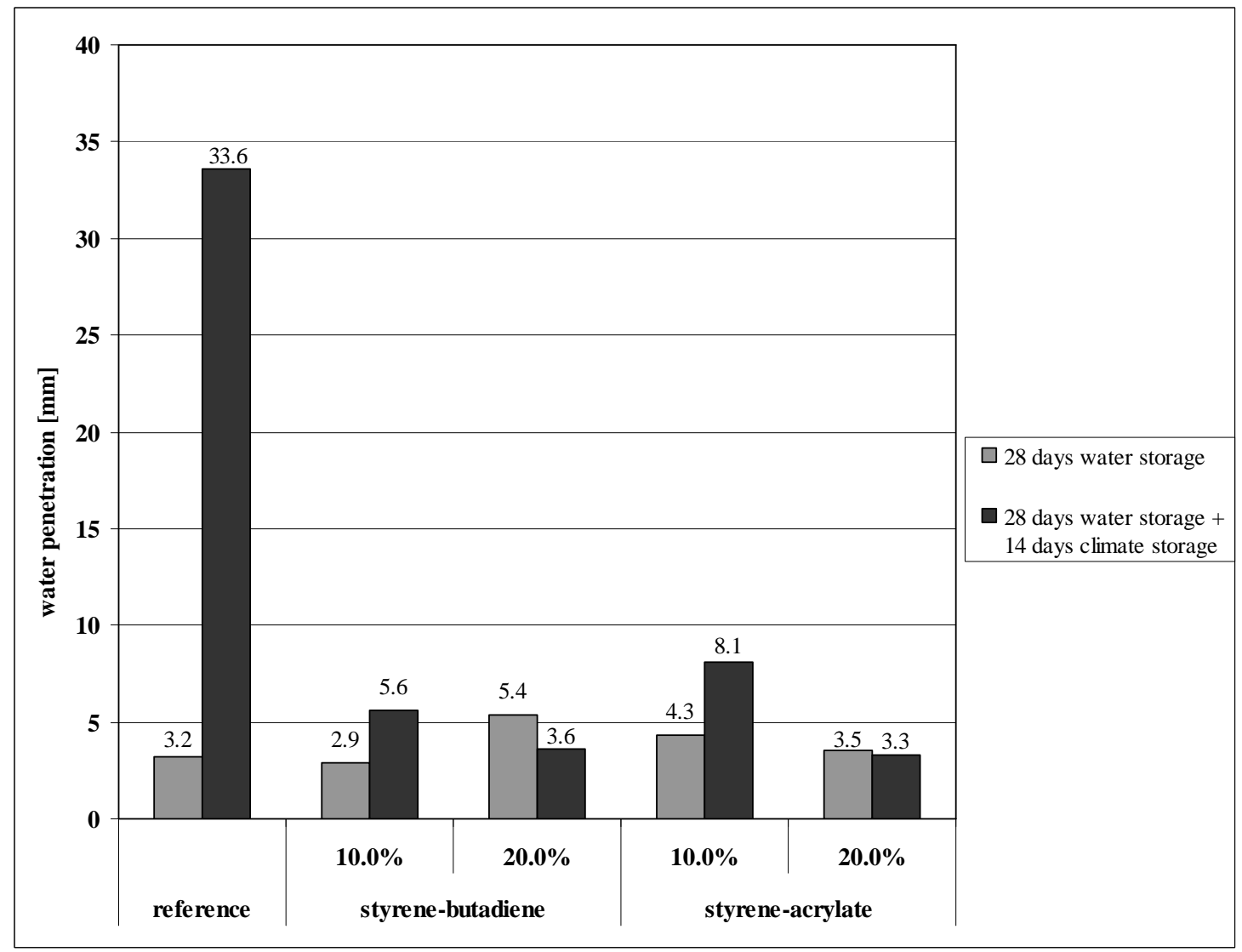

Figure 3: Overview of water penetration after two different kinds of storage

Rapid-Chloride-Migration test. The chlorides in sea water do not attack the mortar itself. However, exceeding the critical chloride content in the mortar near the steel surface might lead to a high corrosion risk. In that case, a localized corrosion occurs, which might spread quickly to the center of the steel tower.

Therefore, a mortar with a high resistance to chloride ingress has to be developed. A dense pore structure and the use of puzzolanic additives can result into such a relative high resistance.

By adding polymer dispersions and thereby decreasing the permeability, a further reduction of the chloride migration coefficient can be achieved. The rapid chloride migration test is a quick tool to test the chloride resistance by applying a voltage [1]. In relation to the depth of cover, the risk for corrosion of the steel surface can be estimated in terms of time.

The first test results after 28 days of storage under water already show a reduction of chloride migration coefficients for the mortars with polymer additives (Fig. 4). When compared to the reference mortar composition, a reduction in the chloride-migration-coefficient from $1.55 \times 10-12$ $\mathrm{m}^{2} / \mathrm{s}$ to $0.80 \times 10-12 \mathrm{~m}^{2} / \mathrm{s}$ was achieved, by using styrene-acrylate of $20 \%$ concentration.

The second set of test results using a subsequent storage in a climate chamber for 14 days followed by a 7 days under water storage show further reductions of chloride migration coefficients for all investigated mix designs. This can be attributed to the ongoing reaction of the contained fly ash and the resulting reduction in porosity. Due to the possibility of polymer film forming, the chloride migration coefficients for the styrene-acrylate modified mortars are even $35 \%$ lower compared to the reference mortar composition.

Therefore it can be summarized that the chloride migration resistance of the investigated mortars is also enhanced by adding polymer dispersions. 


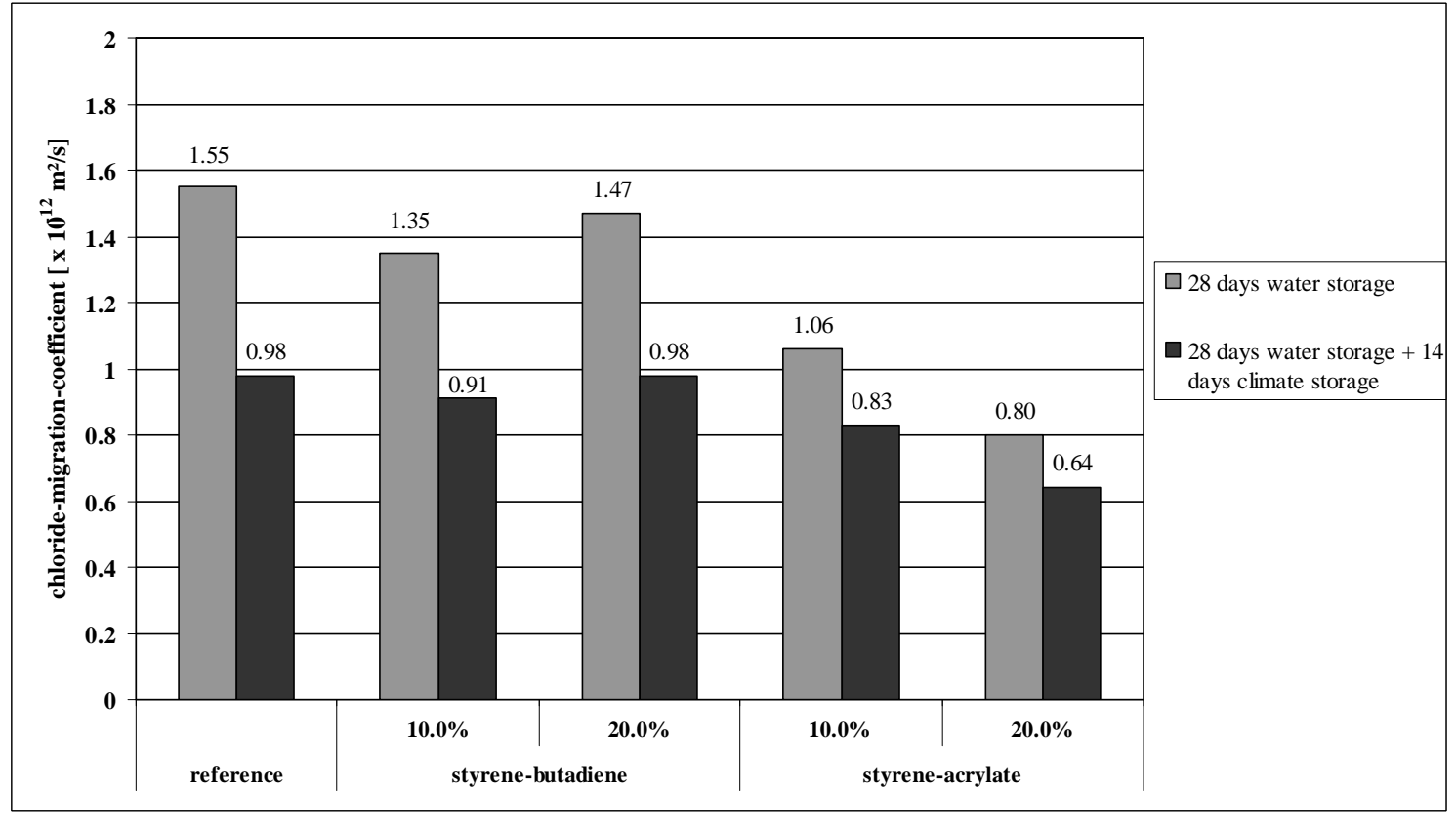

Figure 4: Influence of polymer addition on the chloride-migration-coefficient

Freeze-thaw resistance. Investigations related to the freeze-thaw resistance were carried out with using the CDF-Test according to [2]. After 7 days of storage under water, the specimens were stored in a climatic chamber for 24 days. The drying of the test specimen allowed the film forming of the polymer dispersion. The main criterion for the CDF-test is the spalling of the concrete surface, which is measured in $\mathrm{g} / \mathrm{m}^{2}$. In Fig. 5, it can clearly be seen that only the mortar composition with styrene-acrylate concentration of $20 \%$ reaches a lower value than the $142 \mathrm{~g} / \mathrm{m}^{2}$ determined for the reference mortar composition. Therefore, the excellent freeze-thaw-resistance of the reference mortar composition can not be further improved by polymer addition. However, the acceptance criterion of $1500 \mathrm{~g} / \mathrm{m}^{2}$ is definitely met by all investigated mortars which results are all nearly in the same range.

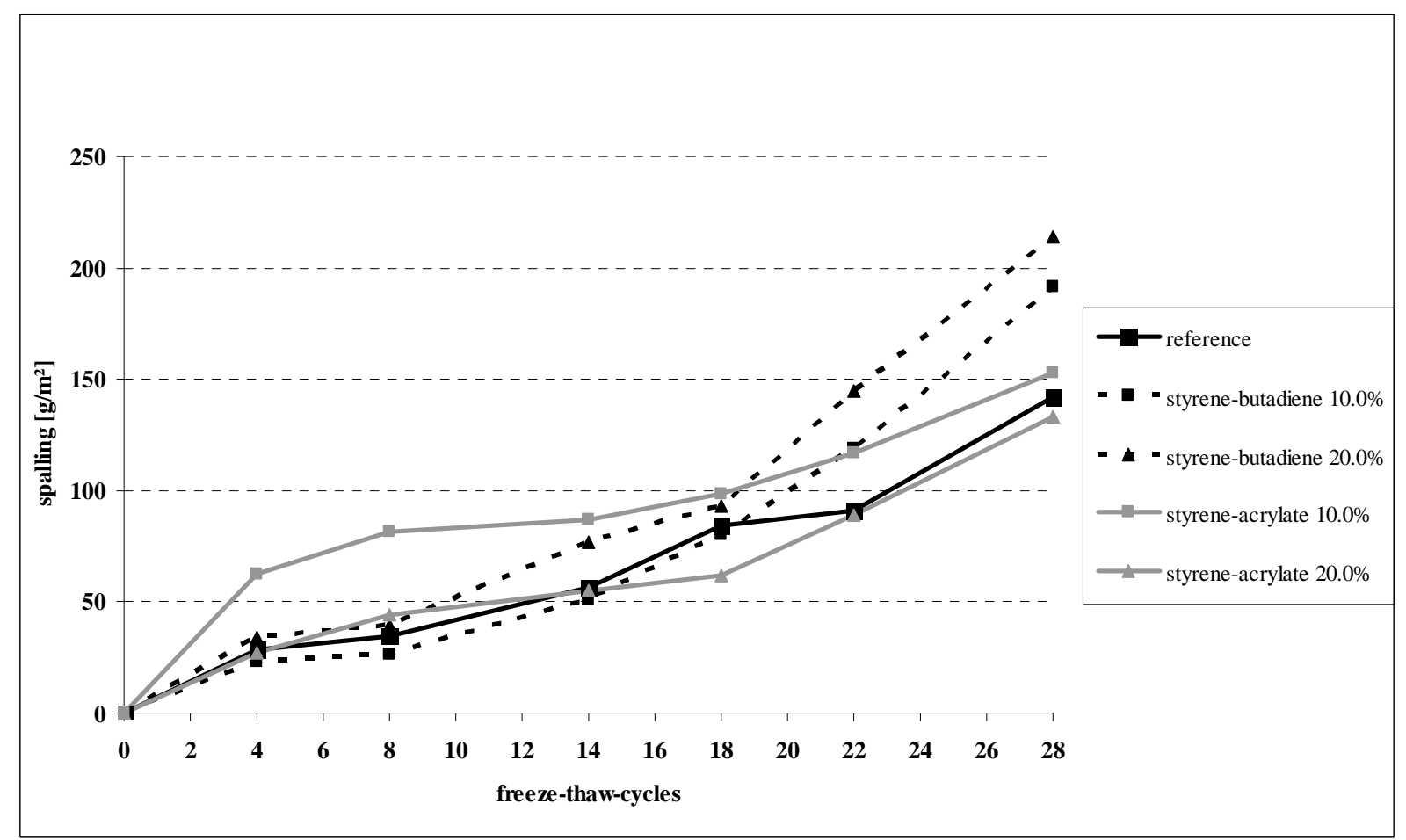

Figure 5: Spalling of the concrete surfaces after several freeze-thaw-cycles 


\section{Conclusions}

The presented test results show that the durability properties of mortars for corrosion protection can be further enhanced by adding polymer dispersions.

The properties of fresh mortar, which are essential for realizing a rather thin corrosion protection layer, do not differ considerably from those of the polymer-free reference mortar composition.

On the other hand, the properties of hardened mortar, which are decisive for improving the durability, are further enhanced. The depth of water penetration in dry specimens can be reduced to $90 \%$ by using a polymer modification through the addition of $20 \%$ concentration of the styreneacrylate. This reduction in water penetration is advantageous with regard to the fluctuation in water level. The resistance against chloride migration can also be increased which lead to a slower progress of the chlorides inside the mortar. Only the freeze-thaw resistance, which was already excellent for the reference mortar composition, could not be increased.

Comparing the different dosages of $10 \%$ and $20 \%$ of polymers (as a mass percentage of the cement content) no major differences have been detected by using either styrene-butadiene or styrene-acrylate. For this reason, usage of a higher concentration is not necessarily essential, providing the option for cost-saving.

Further investigations on the influence of polymer additives on the shrinkage behaviors of these mortars shall be carried out. Regarding this topic some conflicting information can be found in literature. Generally speaking, an increase in shrinkage could possible lead to cracks in the mortar layer, paving the way for a rapid advancement of corrosion-supporting substances towards the steel surface.

Furthermore, a more detailed investigation regarding the effect of storage conditions on the properties of hardened mortar should also be conducted. This is essential to determine whether the formation of the polymer film after storage under water or immediate dry storage affects the properties of the mortar. Due to the low water-cement ratio and the puzzolanic additives, the influence of storing conditions cannot be reliably anticipated without any further investigation.

\section{References}

[1] BAW-Merkblatt „Chlorideindringwiderstand“, Dezember 2004, Bundesanstalt für Wasserbau, Karlsruhe

[2] BAW-Merkblatt „Frostprüfung“, Dezember 2004, Bundesanstalt für Wasserbau, Karlsruhe

[3] Dimmig-Osburg, A., 2002. Einflüsse von Polymeren auf die Mikrostruktur und die Dauerhaftigkeit kunststoffmodifizierter Mörtel (PCC).Dissertation Bauhaus-Universität Weimar, Weimar

[4] Ettel, W.-P., 1998. Kunstharze und Kunststoffdispersionen für Mörtel und Betone. Vbt Verlag Bau U. Technik, Düsseldorf

[5] Lohaus, L., Anders, S., 2004. Effects of polymer modification on the mechanical and fracture properties of high and ultra-high strength concrete. In ICPIC'04, 11. International Congress on Polymers in Concrete (2004), p.183-190, Berlin: BAM

[6] Reinschmidt, A., 2000. Verbesserung der Dichtigkeit und Festigkeit von Mörtel/Beton durch Polymere. Dissertation Universität-Gesamthochschule Siegen, Siegen

[7] Rolfes, R.; Huhn, H.; Schaumann, P.; Schlurmann, T.; Lohaus, L.; Achmus, M., 2010. Ganzheitliches Dimensionierungskonzept für OWEA-Tragstrukturen anhand von Messungen im Offshore-Testfeld alpha ventus. GIGAWIND alpha ventus Jahresbericht 2009, April 2010, Hannover

[8] Weicken, H., 2008. Mineralischer Korrosionsschutz für Offshore-Windenergieanlagen. Diplomarbeit Leibniz Universität Hannover, Hannover 